\title{
Review: angiotensin-converting enzyme inhibitors reduce the progression of non-diabetic renal disease
}

\section{Jafar TH, Schmid CH, Landa M, et al, for the ACE Inhibition in Progressive Renal Disease Study Group. Angiotensin-converting enzyme inhibitors and progression of nondiabetic renal disease. A meta-analysis of patient-level data. Ann Intern Med 2001 Jul 17;135:73-87. \\ QUESTION: In patients with non-diabetic renal disease, are antihypertensive regimens with angiotensin-converting enzyme (ACE) inhibitors effective for slowing the progression of disease?}

\section{Data sources}

Studies were identified by searching Medline (May 1977 to September 1997), scanning abstracts in the proceedings of US and international conferences, scrutinising bibliographies from relevant articles, and contacting investigators for unpublished data.

\section{Study selection}

English-language randomised controlled trials were selected if they compared the effectiveness of antihypertensive regimens containing ACE inhibitors (enalapril, captopril, benazepril, cilazapril, and ramipril) with that of antihypertensive regimens not containing ACE inhibitors (control group) in patients with non-diabetic renal disease, and if they had $\geqslant 1$ year of follow up.

\section{Data extraction}

Data were extracted on sample size, patient characteristics, key components of the intervention, and outcomes. Main outcomes included end-stage renal disease (ESRD), defined as the initiation of long term dialysis treatment, and a composite outcome of a 2 -fold increase in serum creatinine concentrations from baseline values or ESRD. Secondary outcomes included death and a composite outcome of ESRD or death.

\section{Main results}

11 studies (1860 patients; 941 in the ACE inhibitor group and 919 in the control group) were included in the meta-analysis. The incidence rates of ESRD and the combined end point of doubling of baseline serum creatinine concentrations or ESRD were lower in the ACE inhibitor group than in the control group (table) Groups did not differ for death rates or the composite outcome of ESRD or death (table).

\section{Conclusion}

In patients with non-diabetic renal disease, antihypertensive regimens containing angiotensin-converting enzyme (ACE) inhibitors are more effective than regimens without ACE inhibitors for slowing the progression of disease. regimens without ACE inhibitors (control)* lated from data provided by author using a random effects model. tA fixed effects model was used.
Sources of funding: National Institute of Diabetes and Digestive and Kidney Diseases; Agency for Healthcare Research and Quality; Dialysis Clinic, Inc.; Paul Teschan Research Fund; New England Medical Center-St. Elizabeth's Hospital Medical Center Clinical Research

Fellowship Program Merck Research Laboratories.

For correspondence: Dr A S Levey, Division of Nephrology, New England Medical

Center, 750

Washington Street, Box 391, Boston, $M A$ 02111, USA. Fax +1 6176368329

Antihypertensive regimens with angiotensin-converting enzyme (ACE) inhibitors (treatment) v

\begin{tabular}{lllll}
\multirow{2}{*}{$\begin{array}{c}\text { Outcomes at } 2 \text { to } 4 \\
\text { years }\end{array}$} & \multicolumn{2}{l}{ Weighted event rates } & & \\
\cline { 2 - 3 } & Treatment & Control & RRR (95\% Cl) & NNT (Cl) \\
\hline ESRD & $10.5 \%$ & $11.5 \%$ & $34 \%(14$ to 50$)$ & 102 (36 to 114$)$ \\
\hline $\begin{array}{c}\text { Doubling of serum } \\
\text { creatinine or ESRD }\end{array}$ & $15.7 \%$ & $20.3 \%$ & $34 \%(18$ to 47$)$ & 22 (11 to 257$)$ \\
\hline ESRD or death & $11.1 \%$ & $12.7 \%$ & $23 \%(-7$ to 45$)$ & Not significant \\
\hline Death $\dagger$ & $2.4 \%$ & $1.2 \%$ & $63 \%(-219$ to 16$)$ & Not significant \\
\hline
\end{tabular}

${ }^{*} \mathrm{ESRD}=$ end stage renal disease. Other abbreviations defined in glossary; RRR, RRI, NNT, NNH, and Cl calcu-

\section{COMMENTARY}

ACE inhibitors slow the progression of renal disease in type 1 diabetes mellitus independent of the effects of blood pressure (BP). Mounting evidence exists that the same is true in type 2 diabetes mellitus. The benefits of ACE inhibitors may result from lowering BP and reducing proteinuria (effects not specific to ACE inhibitors) and by mitigating the direct effects of angiotensin II on glomerular haemodynamics, inflammation, fibrosis, and sclerosis.

Whether ACE inhibitors benefit patients more than do other antihypertensives in non-diabetic renal disease has not been as convincingly shown. In 5 of the 11 trials included in the meta-analysis by Jafar et al, no benefit from ACE inhibitors was seen. The achieved systolic BP and diastolic BP in many of the studies were lower in the ACE-inhibitor-treated group. Therefore, it could not be concluded that ACE inhibitors were more effective than other antihypertensives, except in their effect on BP.

Patients with greater degrees of proteinuria are at greater risk for progressive renal disease and ESRD. This study and a related meta-analysis by the same authors' ${ }^{1}$ suggest that ACE inhibitors lower urinary protein excretion more than other antihypertensive treatments even after controlling for antihypertensive effects. The reduction in proteinuria with ACE inhibitors is greater in patients with higher levels of urinary excretion. This probably explains the observation that in non-diabetic renal disease, the ability of ACE inhibitors to slow progression of renal disease is most apparent for patients with heavier proteinuria ( $\geq 2$ to $3 \mathrm{~g} / \mathrm{d}$ ). The same benefit has not yet been shown for patients with urine protein levels $<0.5 \mathrm{~g} / \mathrm{d}$.

Sentiment is growing that ACE inhibitors should be the drugs of choice in many hypertensive patients with non-diabetic renal disease and proteinuria. But one important caveat exists: in all but 2 of the studies (both of which are unpublished) $99 \%$ to $100 \%$ of the patients were white; further studies are needed to determine whether a renoprotective effect of ACE inhibitors is also seen in other populations.

1 Jafar TH, Stark PC, Schmid CH, et al. Proteinuria as a modifiable risk factor for the progression of non-diabetic renal disease. Kidney Int 2001;60:1131-40. 